\title{
REFLEXÕES SOBRE A PRODUÇÃO DE ESPAÇOS DE MEMÓRIA EM CONTEXTOS DE JUSTIÇA DE TRANSIÇÃO: O CASO DO MEMORIAL DA RESISTÊNCIA DE SÃO PAULO ${ }^{1}$
}

Talita de Oliveira Trindade ${ }^{2}$

Alessandra de Sá Mello da Costa ${ }^{3}$

\section{Resumo}

O objetivo deste artigo é apresentar algumas reflexões sobre a dinâmica entre organizações, memória e justiça de transição em países da América do Sul. Para isso, discutiremos o processo de constituição e legitimação de locais de memória de resistência, tendo como referência o caso brasileiro do Memorial da Resistência de São Paulo, a partir de dados coletados de fontes documentais e orais, além de visitas técnicas realizadas ao espaço do Memorial.

Palavras-chaves: Organizações. Ditadura. Resistência. Justiça de transição. Lugares de memória.

\section{Reflexiones cerca de la produción de espacios de memoria en contextos de justicia de transición: el caso del Memorial da Resistência de São Paulo}

\section{Resumen}

El objetivo de este artículo es presentar algunas reflexiones sobre la dinámica entre organizaciones, memoria y justicia de transición en países de América del Sur. Para ello, discutiremos el proceso de constitución y legitimación de lugares de memoria de resistencia, teniendo como referencia el caso brasileño del Memorial da Resistência de São Paulo, a partir de datos recolectados de fuentes documentales y orales, además de visitas técnicas realizadas al espacio del Memorial.

Palabras clave: Organizaciones. Dictadura. Resistencia. Justicia de transición. Lugares de memoria.

\section{Reflection on the production of spaces of memory in contexts of transitional justice: the case of the Memorial da Resistência de São Paulo}

\section{Abstract}

\footnotetext{
1 As autoras agradecem à Fundação de Amparo à Pesquisa do Estado do Rio de Janeiro - FAPERJ - pelo suporte financeiro, que viabilizou a coleta de dados da pesquisa.

2 Doutoranda no Programa de Pós-Graduação em Administração de Empresas/IAG da Pontificia Universidade Católica do Rio de Janeiro (PUC-Rio). Professora do IBMEC-RJ. Correio eletrônico: tatrindade@gmail.com.

3 Pontifícia Universidade Católica do Rio de Janeiro (PUC-RJ). Departamento de Administração/IAG. Correio eletrônico: alessandra.costa@iag.puc-rio.br.
} 
The purpose of this article is to present some reflections on the dynamics between organizations, memory and transitional justice in South American countries. To this end, we will discuss the process of constitution and legitimation of resistance memory sites, with reference to the Brazilian case of Memorial da Resistência de São Paulo, based on data collected from documentary and oral sources, as well as technical visits to the Memorial site.

Keywords: Organizations. Dictatorship. Resistance. Transitional justice. Sites of memory.

\section{Introdução}

Organizações, Memória e Justiça de Transição. $O$ encadeamento e a problematização destes temas vem instigando cada vez mais pesquisadores organizacionais a refletirem sobre a atuação de empresas em regimes de excessão. Este é caso, por exemplo, de Stokes e Gabriel (2010) com a discussão sobre Genocídio; de Schrempf-Stirling; Palazzo e Phillips (2016) com a proposta de modelo teórico sobre responsabilidade histórica corporativa; e de Allen e Brown (2016) com seu estudo acerca dos memoriais.

Uma outra trilha possível, também relacionada a essa discussão, diz respeito aos espaços e/ou territórios de memória relacionados com a justiça de transição na América do Sul. Criados em períodos de transição de governos autoritários para governos democráticos, vários pesquisadores já iniciaram tentativas de compreender estes espaços na Argentina (CATELA, 2015; CONTE, 2015); Chile (AGUILERA, 2015) e Uruguai (DRAPER, 2015), sinalizando que o legado da ditadura civil-militar é permeado por disputas acerca do que lembrar e do que esquecer.

A presente pesquisa insere-se nesta discussão, buscando compreender o processo de constituição e legitimação de locais de memória de resistência a partir do caso brasileiro do Memorial da Resistência de São Paulo (MRSP). O MRSP é uma instituição pública, sem fins lucrativos, que está alojada em um edifício que serviu de sede de uma das forças policiais mais violentas do país, o chamado Departamento de Ordem Política e Social do Estado de São Paulo 
REFLEXÕES SOBRE A PRODUÇÃO DE ESPAÇOS DE MEMÓRIA EM CONTEXTOS DE JUSTIÇA DE

TRANSIÇÃO: O CASO DO MEMORIAL DA RESISTÊNCIA DE SÃO PAULO

Talita de Oliveira Trindade | Alessandra de Sá Mello da Costa

(DEOPS). As discussões que levaram à constituição do MRSP começaram em 1979, com a promulgação da Lei de Anistia. O MRSP é, portanto, não apenas um repositório de artefatos e histórias de eventos passados, mas a materialização de um longo processo de disputas políticas e negociações.

\section{Memória, verdade e justiça}

O interesse na preservação, constituição e desenvolvimento de lugares de memória na América do Sul tem se revelado crescente nas últimas décadas, não só do ponto de vista testemunhal e investigativo, mas também para fins de reparação simbólica das vítimas e familiares das ditaduras.

Muitas iniciativas de memorialização, particularmente aquelas que envolvem esforços arquivísticos e museológicos têm sua origem em períodos de Justiça de Transição. No Brasil, a aprovação da Lei da Anistia em 1979 deu início ao processo de abertura e redemocratização do país, ao mesmo tempo em que estabeleceu as condições políticas e em grande parte estruturais para o período de transição que seguiria (ABRÃO E TORELLY, 2015). Demandas por liberdade e reparação têm sido evocadas pela sociedade civil organizada desde a década de 1970, a partir da ideia de uma anistia ampla e irrestrita, em oposição ao que Abrão e Torelly (2015, p. 21) argumentam ser um conceito de anistia constituído sobre “'impunidade e esquecimento' defendido pelo regime militar e seus apoiadores'”. Mais recentemente, a partir de novas articulações entre diversos atores e setores que se mobilizaram, por exemplo, em favor da criação da Comissão Nacional da Verdade, os autores sugerem a emergência de uma "terceira fase de significação social da ideia de 'anistia' no processo transicional brasileiro, que [chamam] de anistia como verdade e justiça" (p. 22). Apesar do Brasil ter sido o último país latino-americano a instaurar uma Comissão da Verdade, estas surgem na região no final dos anos 1980 no âmbito do direito internacional de justiça transicional, pela convergência entre demandas por justiça e transição democrática (Costa e Silva, 2017). No entanto, 
REFLEXÕES SOBRE A PRODUÇÃO DE ESPAÇOS DE MEMÓRIA EM CONTEXTOS DE JUSTIÇA DE

TRANSIÇÃO: O CASO DO MEMORIAL DA RESISTÊNCIA DE SÃO PAULO

Talita de Oliveira Trindade | Alessandra de Sá Mello da Costa

em consonância com os objetivos destas comissões, a justiça transicional também adquire outras configurações, tais como, julgamentos criminais, reformas de instituições políticas, formas de compensação de vítimas e construção de lugares de memória (mais especificamente, na forma de memoriais).

Com organizações e características específicas de cada região e sua historiografia, a rota tortura-resistência-reparação adquire alguns contornos que parecem compartilhados pelos países vizinhos. No Chile, por exemplo, a "ruta de la memoria" de Santiago faz parte dos roteiros turísticos à cidade e envolve visitas a antigos cárceres, memoriais, arquivos e monumentos. $\mathrm{O}$ mesmo acontece em diferentes regiões da Argentina, onde tem-se desde 2006 a chamada Red Federal de Sitios de Memoria, uma organização transversal a diversas jurisdições gerida pela Dirección Nacional de Sitios de Memoria, órgão do Governo Federal responsável por articular a gestão de políticas públicas de memória. Mais recentemente, em junho de 2011, foi sancionada no país a lei $n^{\circ}$ 26.691, que prevê a preservação, sinalização e difusão dos lugares de memória - sabidamente aqueles em que foram perpetradas práticas de violação dos direitos humanos por parte do Estado de maneira clandestina - em virtude de seu valor testemunhal na investigação e tratativa de crimes de lesahumanidade.

No Brasil, as práticas organizativas de memorialização que evidenciam essa rota têm ganhado fôlego e envolvem em sua maioria esforços arquivísticos e museológicos, ações educativas, identificação e sinalização de antigos espaços clandestinos de tortura, além da mobilização do campo patrimonial para fins de tombamento e preservação de alguns desses espaços. É nesse contexto que se dá a constituição do MRSP.

Inaugurado em 2009, o MRSP foi o primeiro espaço de celebração da memória de resistência à ditadura civil-militar que se estabeleceu no Brasil. Trata-se de uma importante iniciativa na promoção e disseminação de memórias 
REFLEXÕES SOBRE A PRODUÇÃO DE ESPAÇOS DE MEMÓRIA EM CONTEXTOS DE JUSTIÇA DE

TRANSIÇÃO: O CASO DO MEMORIAL DA RESISTÊNCIA DE SÃO PAULO

Talita de Oliveira Trindade | Alessandra de Sá Mello da Costa

alternativas àquelas dominantes sobre os eventos ocorridos ao longo desse período, que em grande parte estão alicerçadas em um discurso conciliatório, característico do próprio modelo de anistia adotado no país: parcial e restritivo. A despeito disso, também é verdade que a estabilidade e a legitimidade da memória dominante, muitas vezes representada pela ideia de uma memória nacional, são por vezes questionadas em momentos de transição entre regimes, na medida em que memórias anteriormente silenciadas passam a ser evocadas e articuladas em vias de promoverem a problematização das narrativas que constituem a memória dominante.

\section{De lugar de tortura a lugar de memória de resistência: um longo caminho}

O prédio que hoje abriga o Memorial da Resistência de São Paulo foi projetado pelo escritório de Ramos Azevedo e edificado em 1914, no terreno da São Paulo Railway que havia sido cedido para a Estrada de Ferro Sorocaba pelo período de 76 anos. No entanto, em 1939, a Estrada de Ferro desocupou as instalações, para dar lugar à Secretaria de Segurança Pública (NEVES, 2011). Pouco tempo depois, em 1942, lá se instalou o Departamento de Ordem Política e Social DOPS, localmente chamado de Departamento Estadual de Ordem Política e Social de São Paulo - DEOPS/SP. Estabelecido em 1924, O DOPS era parte aparato administrativo-legal de vigilância, controle e repressão do governo, e tinha como uma de suas atribuições exercer a função de polícia política em vias de uma suposta manutenção da ordem político-social.

As disputas que levaram à constituição do MRSP tiveram início em 1976, quando com os primeiros debates acerca dos possíveis usos e apropriações do prédio dado seu grande valor arquitetônico e histórico. Quase uma década antes, em 1968, fora criado o Conselho de Defesa do Patrimônio Histórico, Arqueológico, Artístico e Turístico (Condephaat), que se tornou o órgão responsável pelo tombamento de bens e imóveis no estado de São Paulo. Dentre as suas atribuições estavam o mapeamento e a preservação de 
REFLEXÕES SOBRE A PRODUÇÃO DE ESPAÇOS DE MEMÓRIA EM CONTEXTOS DE JUSTIÇA DE TRANSIÇÃO: O CASO DO MEMORIAL DA RESISTÊNCIA DE SÃO PAULO

Talita de Oliveira Trindade | Alessandra de Sá Mello da Costa

construções que representassem os ciclos sociais e econômicos da cidade de São Paulo (ALMEIDA, 2014). Assim, em 1976, a equipe técnica do Condephaat encaminhou uma representação para o Secretário Executivo do Conselho em que indicavam o tombamento do prédio ocupado pelo DEOPS/SP, além de outros 19 imóveis. O pedido de vistoria da área interna do edifício foi negado pelo então diretor geral do DEOPS/SP, Romeu Tuma, que alegou “questões de segurança" como justificativa da negativa. O processo foi arquivado em 1980. Com o encerramento das atividades do DEOPS/SP em 1983, o processo de tombamento foi reaberto no ano seguinte, quando também ocorreu a exposição "Pequenas Inssurreições - Memórias", organizada pela Associação Brasileira de Imprensa de São Paulo (ABI-SP) -movimentos ilustrativos da mobilização de atores interessados em denunciar os locais utilizados pelo regime militar e desvelar suas práticas clandestinas. Por fim, em 1986 o prédio recebeu a indicação de tombamento, ainda que a resolução viesse a ser publicada somente em 1999. 
REFLEXÕES SOBRE A PRODUÇÃO DE ESPAÇOS DE MEMÓRIA EM CONTEXTOS DE JUSTIÇA DE TRANSIÇÃO: O CASO DO MEMORIAL DA RESISTÊNCIA DE SÃO PAULO Talita de Oliveira Trindade | Alessandra de Sá Mello da Costa

\section{CONDEPHAAT - Conselho de Defesa do Patrimônio Histórico, Arqueológico, Artístico e Turístico do Estado de São Paulo.}

Resolução SC 28/99, de 08 de julho de 1999, publicado no DOE 09/07/99, p. 24

Dispõe sobre o tombamento do edifício do antigo DOPS

O Secretário da Cultura, nos termos do artigo $1^{\circ}$ do Decreto-Lei $n^{\circ} 149$, de 15 de agosto de 1969 e do Decreto 13.426, de 16 de março de 1979, cujos artigos 134 a 149 permanecem em vigor por força dos artigos 187 e 193 do Decreto $n^{\circ} 20.955$, de $1^{\circ}$ de junho de 1983,

\section{Resolve:}

Artigo $1^{\circ}$ - Fica tombado como bem cultural de interesse para a memória social paulista o edifício localizado na Praça General Osório, no 66, 88, 120 e 136, o "antigo DOPS", construído para abrigar armazéns da Estrada de Ferro Sorocabana, foi ocupado parcial e temporariamente pela direção da mesma empresa até o término das obras da Estação Júlio Prestes, de 1951 a 1953, o do estado e, em seguida, pelo DOPS, Departamento de Ordem Política e Social da Secretaria de Segurança Pública do Estado de São Paulo. Foi projetado pelo Escritório de Ramos de Azevedo, sua importância arquitetônica é grande e decorre principalmente do seu partido arquitetônico. O espaço é definido de forma racional e organiza os ambientes, amplos, entre as prumadas verticais de circulação. Os sistemas estruturais adotados associam elementos modulares em ferro às duas torres de alvenaria portante e resolvem tecnicamente o espaço pretendido. No conjunto das celas, produto da ocupação do edifício pelo DOPS, reside parte significativa de seu valor histórico. Tal conjunto será preservado juntamente com os elementos originais do projeto.

Artigo $2^{\circ}$ - Fica o CONDEPHHAT - Conselho de Defesa do Patrimônio Histórico, Arqueológico, Artístico e Turístico do Estado de São Paulo autorizado a inscrever no Livro de Tombo o referido bem para os devidos efeitos legais.

Artigo $3^{\circ}$ - Esta Resolução entrará em vigor na data da sua publicação.

Figura 1: Resolução SC 28/99 - Tombamento do edifício do antigo DOPS

(Prefeitura SP, 1999)

Com isso, se iniciava um longo processo de disputas pela apropriação e uso do espaço

Revista Brasileira de Estudos Organizacionais .v. 4, n. 2, p. 407-436, dez. 2017, eISSN: 2447-4851

Doi 10.21583/2447-4851.rbeo.2017.v4n2.105

Sociedade Brasileira de Estudos Organizacionais 
Essas disputas envolveram diversos atores sociais, que ao longo do tempo participaram de uma série de debates e negociações acerca do propósito, localização, léxico, significados e do próprio projeto museal do MRSP.

A esse respeito, Pollak (1989, p. 5) afirma que “[...] uma vez que as memórias subterrâneas conseguem invadir o espaço público, reivindicações múltiplas e dificilmente previsíveis se acoplam a essa disputa da memória". A evocação dessas múltiplas vozes mostrou-se absolutamente relevante no caso brasileiro, uma vez que foi a partir dos relatos e reivindicações de ex-presos políticos que se iniciou o trabalho de organização da sua memória enquanto grupo, bem como o debate em prol da verdade, justiça e reparação desses indivíduos e familiares. A musealização do espaço - ou a tratativa do espaço como documento -, foi fundamental não só para fins de reparação das vítimas, mas para ancoragem e ressignificação das narrativas acerca das práticas de violação dos direitos humanos e resistência que embora representem um crime contra a humanidade, enquanto práticas estavam circunscritas àquele local.

A constituição de lugares de memória, como é o caso do MRSP, torna-se relevante no processo de organização e legitimação dessas memórias alternativas - "são lugares, com efeito nos três sentidos da palavra, material, simbólico e funcional, simultaneamente, somente em graus diversos" (NORA, 1993, p. 21). Além de servirem como repositório de documentos, artefatos e relatos, os lugares de memória mitigam os efeitos do afastamento temporal com o passado, resgatam o repertório imagético dos eventos ocorridos e (potencialmente) promovem o debate acerca dos seus efeitos no tempo presente. A esse respeito, Inêz Soares e Renan Quinalha acrescentam que, em um sentido mais amplo e atual, os lugares de memória ainda servem como “mecanismo extrajudicial para reparação simbólica e um meio de envolver o Estado em sua gestão, expressando pública e oficialmente o repúdio às violações cometidas por seus agentes e muitas vezes negadas" (SOARES E QUINALHA, 2011, p. 80). 
REFLEXÕES SOBRE A PRODUÇÃO DE ESPAÇOS DE MEMÓRIA EM CONTEXTOS DE JUSTIÇA DE

TRANSIÇÃO: O CASO DO MEMORIAL DA RESISTÊNCIA DE SÃO PAULO

Talita de Oliveira Trindade | Alessandra de Sá Mello da Costa

\section{Memorial do Cárcere}

Logo após a publicação da resolução de tombamento foram iniciadas as obras no edifício, em que se cogitou ocupar com uma escola de música. No entanto, por determinação do decreto de tombamento, as celas e o corredor utilizados para banho de sol dos presos políticos durante o funcionamento do DEOPS/SP deveriam ser conservados. Almeida (2014) aponta que muitas foram as disputas pelo direito de uso, apropriação e ressignificação do espaço: a Escola Livre de Música via no prédio a possibilidade de alocação da sua nova sede, o governo de São Paulo identificava no projeto da Escola Superior de Música uma grande oportunidade de investimento estrangeiro e ex-militantes, expresos políticos e demais grupos políticos viam no Museu do Cárcere uma possibilidade de rememoração e compartilhamento público/denunciativo de suas memórias. A mídia, por sua vez, adotou uma narrativa em tono da "higienização simbólica" do espaço, promovida pelo abafamento e substituição dos sons oriundos das práticas de tortura perpetradas pelos militares pelos sons orquestrais produzidos na Escola Superior de Música.

Com o fim das obras de restauração, em 2002, e já realizada a transferência do prédio para a tutela da Secretaria de Estado da Cultura, cogitou-se a possibilidade de que o edifício se tornasse endereço do Museu do Imaginário do Povo Brasileiro, projeto que acabou sendo cancelado. As instalações utilizadas pelo DEOPS/SP, no entanto, foram mantidas e deram lugar ao que, como resultado das disputas entre diversos grupos de interesse, foi chamado de Memorial do Cárcere, criado em janeiro de 2002. 
DECRETO No 46.508 ,

\section{DE 21 DE JANEIRO DE 2002}

Cria, na Secretaria da Cultura, o Memorial do Cárcere e dá providências correlatas

GERALDO ALCKMIN, Governador do Estado de São Paulo, no uso de suas atribuiçōes legais,

Considerando a importância da preservação de símbolos da resistência à repressão e da difusão dos ideais de liberdade;

Considerando a oportunidade de se promover açōes educativas que consolidem os princípios democráticos; e

Considerando a necessidade da manutenção dos valores democráticos,

Decreta:

Artigo $1^{\circ}$ - Fica criado, na Secretaria da Cultura, o Memorial do Cárcere, diretamente subordinado ao Diretor do Departamento de Museus e Arquivos - DEMA, com sede no Largo General Osório n 66, prédio do antigo Departamento de Ordem Política e Social - DOPS.

§ 1- O Memorial criado por este artigo terá como sede de suas atividades a área prisional do prédio do antigo DOPS.

§ 2 - O Memorial do Cárcere tem nível de Divisão.

Artigo $2^{\circ}$ - 0 Memorial do Cárcere tem por objetivo estimular o exercício da cidadania e seus valores democráticos, por meio de mostras, exposiçōes e outras manifestações artísticas e culturais.

Artigo $3^{\circ}$ - Em decorrência do disposto no artigo $1^{\circ}$ deste decreto, fica acrescentado ao artigo 12 do
Decreto $n^{\circ} 20.955$, de $1^{\circ}$ de junho de 1983, o inciso $X$, com a seguinte redação:

"X - Memorial do Cárcere.".

Artigo $4^{\circ}$ - A Academia de Música de São Paulo, criada pelo Decreto $\mathrm{n}^{\circ} 42.991$, de $1^{1}$ de abril de 1998 , terá sua nova sede definida mediante resolução do Secretário da Cultura.

Artigo $5^{\circ}$ - Este decreto entra em vigor na data de sua publicação.

Palácio dos Bandeirantes, 21 de janeiro de 2002

GERALDO ALCKMIN

Marcos Ribeiro de Mendonça

Secretário da Cultura

Joâo Caramez

Secretário-Chefe da Casa Civil

Antonio Angarita

Secretário do Governo e Gestão Estratégica

Publicado na Secretaria de Estado do Governo e Gestão Estratégica, aos 21 de janeiro de 2002.

\section{De Liberdade a Resistência}

Cerca de seis meses após a criação do Memorial do Cárcere, o mesmo foi revogado, dando lugar ao Memorial da Liberdade, que seria instalado na área prisional do prédio em que funcionava o DEOPS/SP. 


\section{REFLEXÕES SOBRE A PRODUÇÃO DE ESPAÇOS DE MEMÓRIA EM CONTEXTOS DE JUSTIÇA DE TRANSIÇÃO: O CASO DO MEMORIAL DA RESISTÊNCIA DE SÃO PAULO \\ Talita de Oliveira Trindade |Alessandra de Sá Mello da Costa}

\section{DEC no 46.900 de 5/7/2002}

Cria, na Secretaria da Cultura, o Memorial da Liberdade e dá providências correlatas

GERALDO ALCKMIN, Governador do Estado de São Paulo, no uso de suas atribuicões leqais, à vista da manifestação do Secretário da Cultura,

Considerando que o Estado deve qarantir e apoiar sempre a criação e o desenvolvimento de novos espaços e instituições para a promoção dos direitos do homem e das liberdades fundamentais;

Considerando que o Estado tem o dever de promover e facilitar a educação e o conhecimento dos direitos do homem e das liberdades fundamentais através de atividades de formação, investigação e estudos para assim reforçar a compreensão, a tolerância e a paz;

Considerando a importância da preservação e da difusão dos ideais de liberdade;

Considerando a oportunidade de se promover ações educativas que consolidem os princípios democráticos; e

Considerando a necessidade da manutenção dos valores democráticos,

Decreta:

Artigo $1^{\circ}$ - Fica criado, na Secretaria da Cultura, o Memorial da Liberdade, diretamente subordinado ao Diretor do Departamento de Museus e Arquivos - DEMA, com sede no Largo General Osório n 66 , prédio do antigo Departamento de Ordem Política e Social - DOPS.

$\S 1^{\circ}$ - O Memorial criado por este artigo terá como sede de suas atividades a área prisional do prédio do antigo DOPS.

$\S 2^{\circ}$ - O Memorial da Liberdade tem nível de Divisão.

Artigo $2^{\circ}$ - O Memorial da Liberdade tem por objetivo estimular o exercício da cidadania e seus valores democráticos, por meio de mostras, exposições, formação de acervo, seminários, publicacões e outras manifestações artísticas e culturais.

Artigo $3^{\circ}$ - Em decorrência do disposto no artiqo $1^{\circ}$ deste decreto, fica acrescentado ao artiqo 12 do Decreto $n^{\circ} 20.955$, de $1^{\circ}$ de junho de 1983, o inciso $X$, com a seguinte redação: "X - Memorial da Liberdade.".

Artigo $4^{\circ}$ - Este decreto entra em vigor na data de sua publicação, revogando-se as disposições em contrário, em especial o Decreto n० 46.508, de 21 de janeiro de 2002.

Palácio dos Bandeirantes, 5 de julho de 2002

GERALDO ALCKMIN; Marcos Ribeiro de Mendonça, Secretário da Cultura; Rubens Lara,

Secretário-Chefe da Casa Civil; Dalmo Nogueira Filho, Secretário do Governo e Gestão Estratégica

Publicado na Secretaria de Estado do Governo e Gestão Estratégica, aos 5 de julho de 2002.

Figura 3: Decreto $n^{\circ} 46.900$ - Memorial da Liberdade (Neves, 2011)

O Memorial da Liberdade, sob gestão do Arquivo Público do Estado de São Paulo, foi inaugurado em julho de 2002 sob inúmeras críticas às obras de restauração feitas no espaço carcerário, que apagaram boa parte das memórias e inscrições feitas pelos ex-presos que estiveram ali durante o regime militar (ANTONINI, 2012). Conforme nos mostra Fecher (2015), a descaracterização do espaço físico e o conteúdo exposto para os visitantes foram significativamente questionados, uma vez que as obras de restauração fizeram desaparecer de 
REFLEXÕES SOBRE A PRODUÇÃO DE ESPAÇOS DE MEMÓRIA EM CONTEXTOS DE JUSTIÇA DE

TRANSIÇÃO: O CASO DO MEMORIAL DA RESISTÊNCIA DE SÃO PAULO

Talita de Oliveira Trindade | Alessandra de Sá Mello da Costa

celas inteiras a inscrições nas portas e paredes do que havia sido preservado no complexo prisional.

A própria escolha do léxico "liberdade" foi repudiada pelos exprisioneiros, perseguidos e demais militantes, que viam nele uma aproximação com uma narrativa de esquecimento. De acordo com o depoimento de um dos ex-prisioneiros envolvido no movimento de musealização, "com certeza não está correto o nome Memorial da Liberdade, porque ali houve tudo menos liberdade" (ver: FECHER, 2015, p. 80). Assim, paralelamente ao processo de reparação pecuniária dos ex-presos, em 2007, representantes de diversos grupos organizados - como o Fórum Permanente de ex-Presos Políticos do Estado de São Paulo, o Conselho Estadual de Desefa dos Direitos da Pessoa Humana (CONDEPE) - e demais ex-militantes demandaram a reformulação do projeto museológico do MRSP, de modo que este se tornasse de fato representativo das suas memórias e narrativas, além de incorporar um elemento pedagógico em sua constituição. Como resultado do diálogo entre militantes, historiadores e museólogos, “em 2007 o projeto museológico do Memorial da Resistência é entregue à Pinacoteca do Estado e inaugurado, posteriormente, em 24 de janeiro de 2009” (ALMEIDA, 2014, p. 283).

A escolha pelo léxico "resistência" aproxima esse lugar de memória das narrativas em torno da defesa dos direitos humanos e comunica amplamente as ações realizadas pelo Memorial, que capitaneia uma série de programas e projetos de natureza educativa e museológica, além de ser o sexto museu mais visitado na cidade de São Paulo, com a média de 70.000 visitantes anualmente.

O projeto museológico do MRSP previa não só a reconstituição do espaço do ponto de vista arquitetônico, mas histórico e memorialístico, dessa vez, a partir da coleta de testemunhos e uma série de diligências feitas por expresos ao conjunto prisional, a fim de reconstituir as características físicas do espaço para preservação.

Revista Brasileira de Estudos Organizacionais .v. 4, n. 2, p. 407-436, dez. 2017, eISSN: 2447-4851

Doi 10.21583/2447-4851.rbeo.2017.v4n2.105

Sociedade Brasileira de Estudos Organizacionais 
REFLEXÕES SOBRE A PRODUÇÃO DE ESPAÇOS DE MEMÓRIA EM CONTEXTOS DE JUSTIÇA DE TRANSIÇÃO: O CASO DO MEMORIAL DA RESISTÊNCIA DE SÃO PAULO

Talita de Oliveira Trindade | Alessandra de Sá Mello da Costa

Figura 4: Painel - "Ex-Presos Políticos que deram testemunhos" (Visita técnica ao MRSP, maio/2016) 
REFLEXÕES SOBRE A PRODUÇÃO DE ESPAÇOS DE MEMÓRIA EM CONTEXTOS DE JUSTIÇA DE TRANSIÇÃO: O CASO DO MEMORIAL DA RESISTÊNCIA DE SÃO PAULO Talita de Oliveira Trindade | Alessandra de Sá Mello da Costa

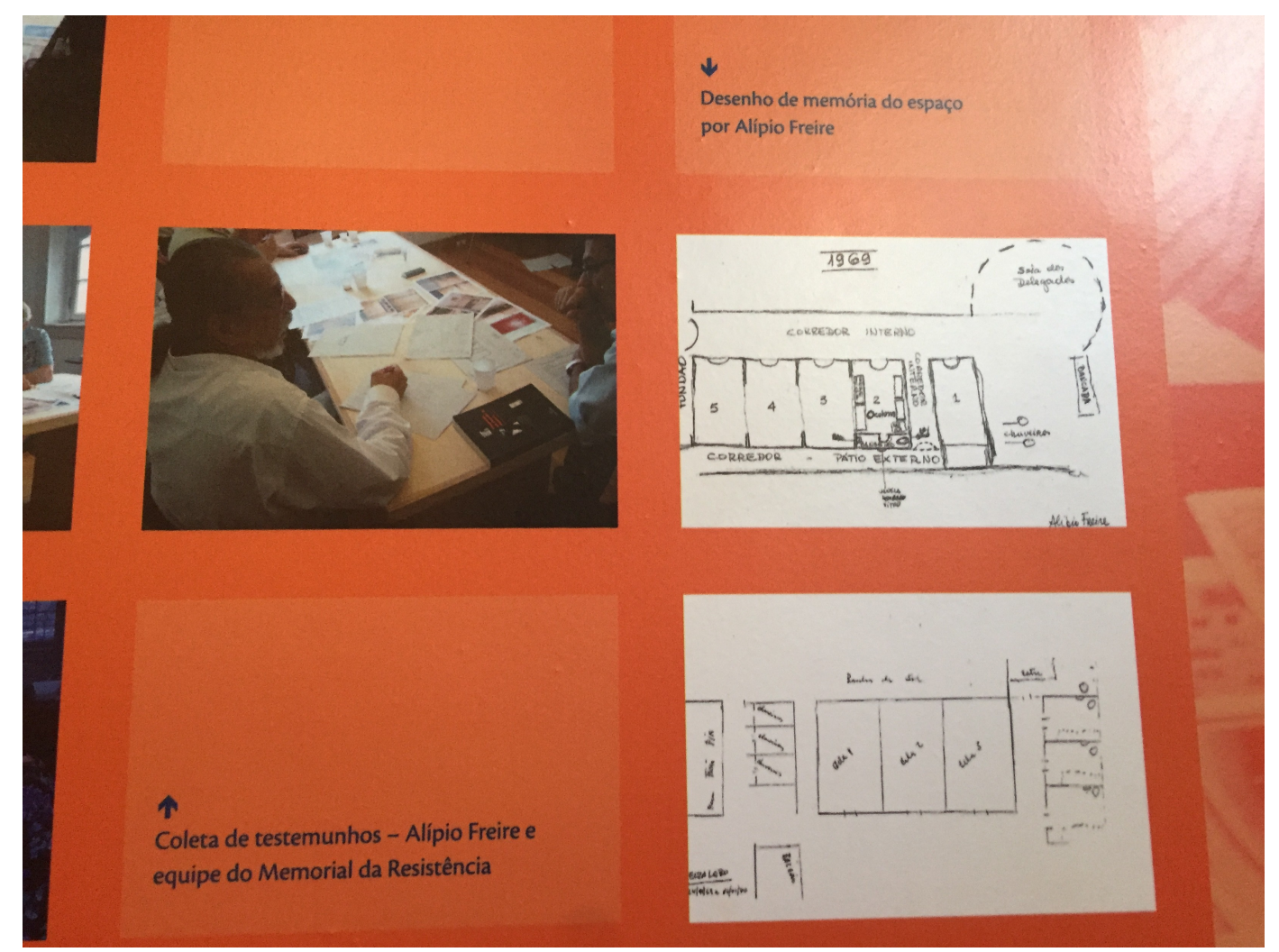

Figura 5: Painel - Desenho de memória do espaço das celas a partir da coleta de testemunhos (Visita técnica ao MRSP, maio/2016)

Revista Brasileira de Estudos Organizacionais .v. 4, n. 2, p. 407-436, dez. 2017, eISSN: 2447-4851 Doi 10.21583/2447-4851.rbeo.2017.v4n2.105

Sociedade Brasileira de Estudos Organizacionais 
REFLEXÕES SOBRE A PRODUÇÃO DE ESPAÇOS DE MEMÓRIA EM CONTEXTOS DE JUSTIÇA DE

TRANSIÇÃO: O CASO DO MEMORIAL DA RESISTÊNCIA DE SÃO PAULO

Talita de Oliveira Trindade | Alessandra de Sá Mello da Costa

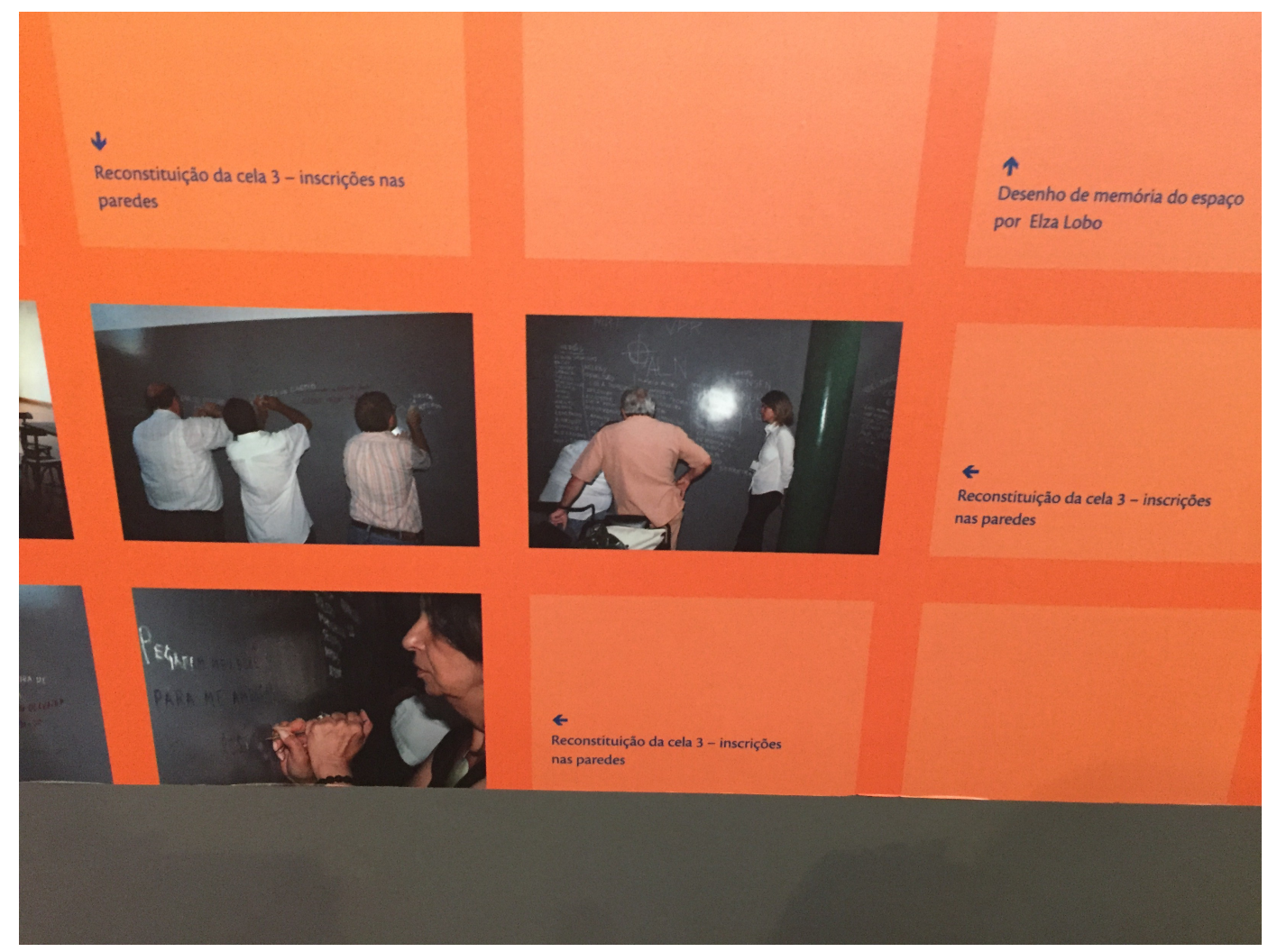

Figura 6: Painel - Reconstituição da cela 3, com apoio de ex-presos políticos (Visita técnica ao MRSP, maio/2016)

O resultado desse esforço foi a reconstituição de quatro celas do complexo prisional, algumas delas com a reconstituição de algumas inscrições, além da área de banho de sol a que os ex-presos políticos tinham acesso uma vez por semana.

Revista Brasileira de Estudos Organizacionais .v. 4, n. 2, p. 407-436, dez. 2017, eISSN: 2447-4851 
REFLEXÕES SOBRE A PRODUÇÃO DE ESPAÇOS DE MEMÓRIA EM CONTEXTOS DE JUSTIÇA DE TRANSIÇÃO: O CASO DO MEMORIAL DA RESISTÊNCIA DE SÃO PAULO

Talita de Oliveira Trindade | Alessandra de Sá Mello da Costa

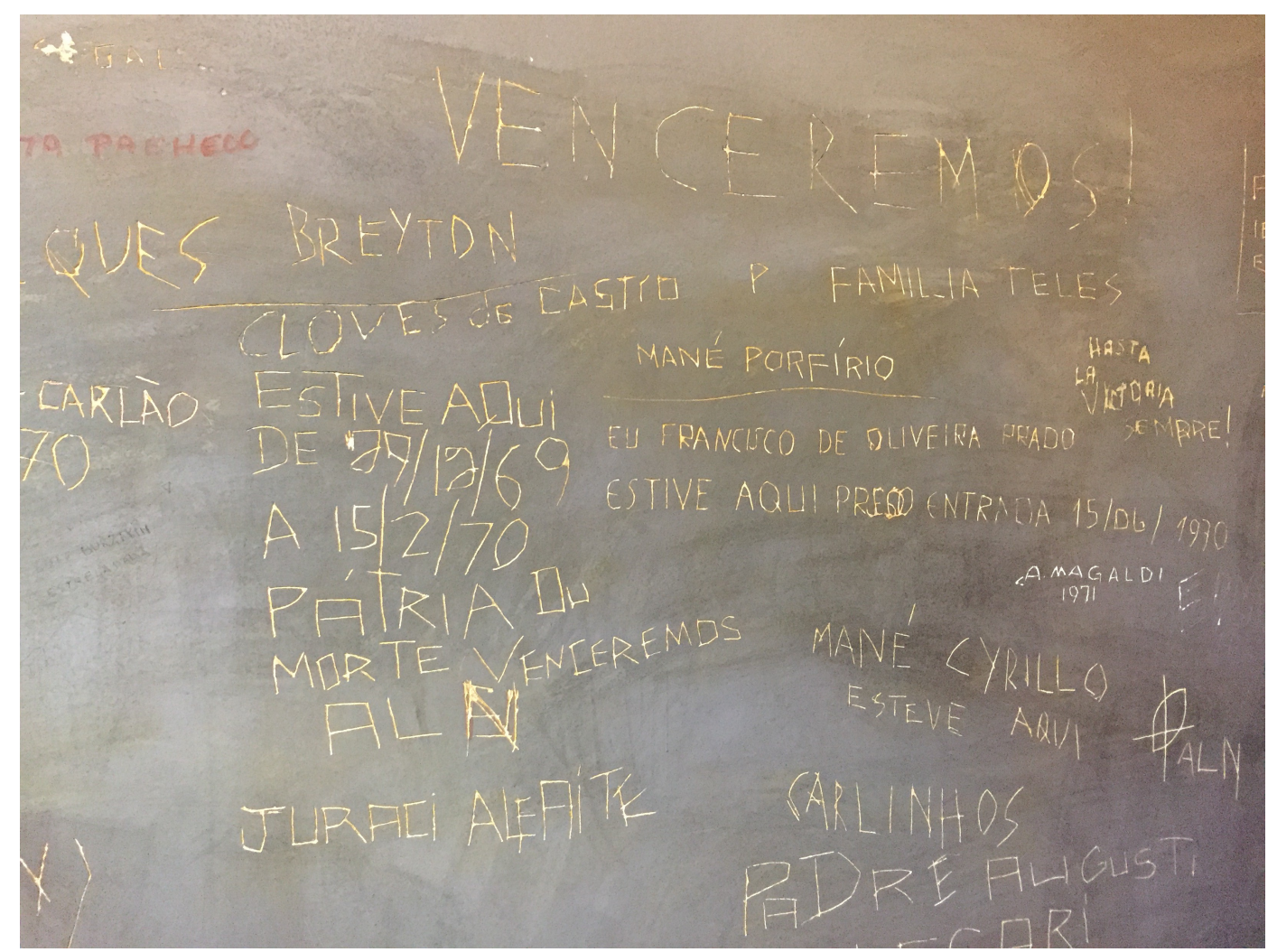

Figura 7: Reconstituição das celas (Visita técnica ao MRSP em maio/2016)

Revista Brasileira de Estudos Organizacionais .v. 4, n. 2, p. 407-436, dez. 2017, eISSN: 2447-4851 Doi 10.21583/2447-4851.rbeo.2017.v4n2.105

Sociedade Brasileira de Estudos Organizacionais 


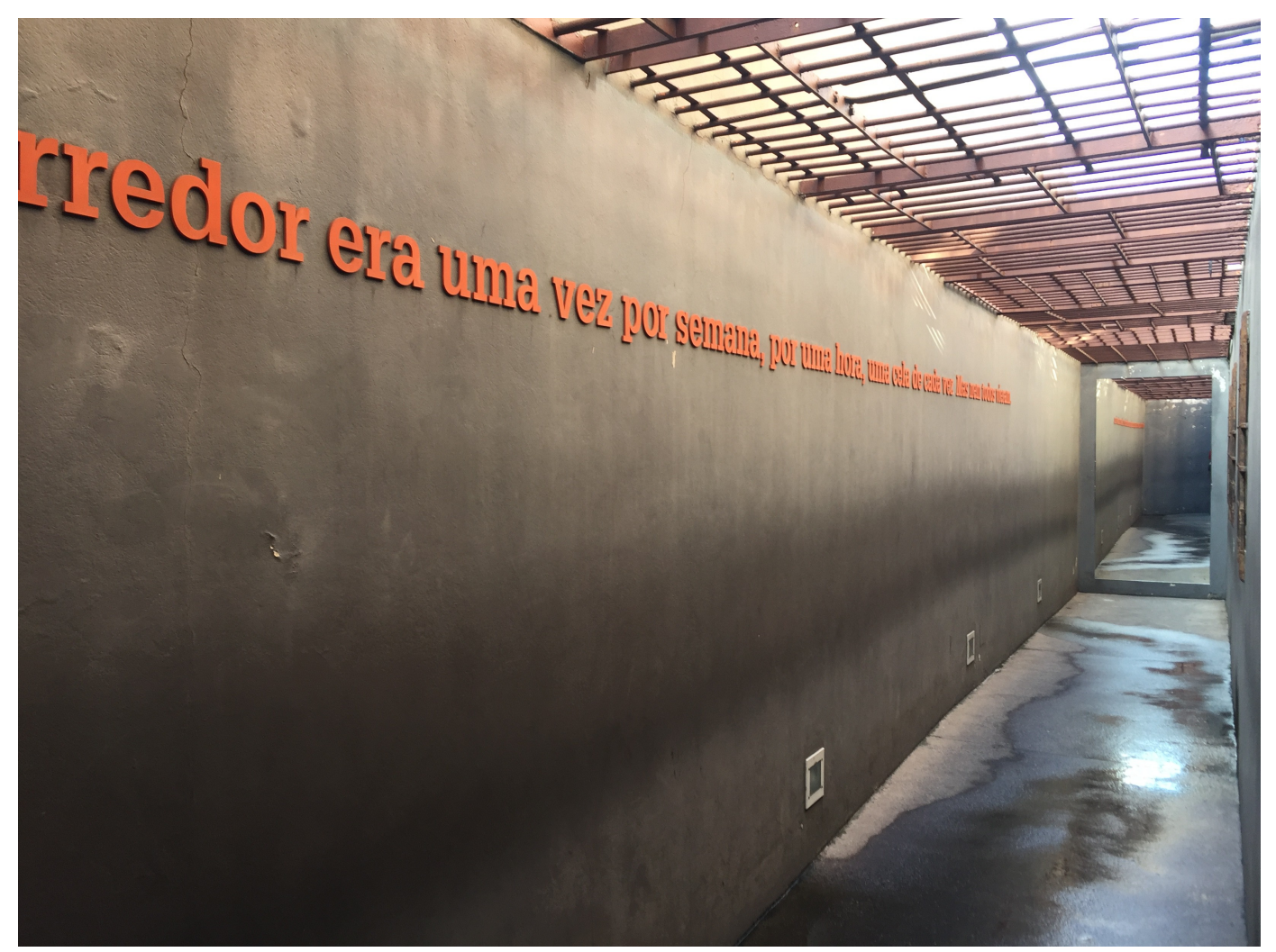

Figura 8: Reconstituição do corredor para banho de sol (Visita técnica ao MRSP em

$$
\text { maio/2017) }
$$

\section{Território memória coletiva}

A emergência de lugares de memória se dá na medida em que, segundo Pierre Nora (1993), as condições de existência dos meios de memória deixam de existir. Nesse sentido, os lugares de memória carregam em si a ideia de uma dada vontade de memória e operam como marcos testemunhos de outros tempos, que se mantém por meio de documentos, monumentos, arquivos, museus, celebrações e diversos outros mecanismos de memorialização.

Os lugares de memória nascem e vivem do sentimento que não há memória espontânea, que é preciso criar arquivos, que é preciso manter aniversários, organizar celebrações, pronunciar elogios fúnebres, notariar atas, porque essas operações não são naturais. É 
por isso a defesa, pelas minorias, de uma memória refugiada sobre focos privilegiados e enciumadamente guardados nada mais faz do que levar à incandescência a verdade de todos os lugares de memória. [...] São bastiões sobre os quais se escora. Mas se o que eles defendem não estivesse ameaçado, não se teria, tampouco, a necessidade de construí-los (NORA, 1993, p. 13).

Embora o termo tenha sido originalmente cunhado pelo autor tendo em vista as transformações ocorridas na sociedade francesa que, em sua leitura, caminhavam para o esfacelamento de uma identidade nacional, a discussão sobre os lugares de memória se aplica a outras sociedades em contextos mais contemporâneos, particularmente àquelas que passaram por processos de justiça de transição. Esses processos criam as condições de escuta necessárias para que vozes e narrativas silenciadas durante períodos ditatoriais, sabidamente traumáticos e com efeitos em diversas esferas sociais, emerjam e passem a representar uma alternativa às memórias dominantes (POLLAK, 1989). No Brasil, a Comissão Nacional da Verdade, por meio do Grupo de Trabalho sobre "Estrutura de Repressão", permitiu a problematização de espaços antes usados como centros de tortura a partir das narrativas de expresos políticos, como foi o caso do prédio que atualmente abriga o Memorial da Resistência de São Paulo.

Assim, neste artigo assumimos que o Memorial da Resistência de São Paulo é, ao mesmo tempo, um lugar de memória e um território de memória (CATELA, 2001). O primeiro termo aponta para a tripla concepção do espaço do Memorial: (1) material, na medida em que as memórias alternativas sobre o antigo espaço de tortura passam a ser hospedadas e compartilhadas, permitindo que outros indivíduos as acessem por meio dos sentidos (nas visitas às celas, leitura das cartas etc); (2) funcional, uma vez que o Memorial ancora a construção e disseminação de novas narrativas e práticas (educativas, reparatórias etc) que, em última instância, suportam a reconfiguração da memória coletiva; e (3) simbólica, visto que revela essas memórias e esse 
REFLEXÕES SOBRE A PRODUÇÃO DE ESPAÇOS DE MEMÓRIA EM CONTEXTOS DE JUSTIÇA DE

TRANSIÇÃO: O CASO DO MEMORIAL DA RESISTÊNCIA DE SÃO PAULO

Talita de Oliveira Trindade| Alessandra de Sá Mello da Costa

movimento pode contribuir com a construção de um senso de identidade revistado por parte daqueles diretamente impactados pelos feitos da ditadura civil-militar, tanto quanto por uma maior parcela da população, que encontra no espaço a possibilidade de ressignificação das ideias de militância e resistência.

Ludmila Catela (2001, p. 10) propõe que a expressão territórios da memória, por "enfatiza conquista, litígio, extensão de fronteiras e, acima de tudo, disputa. Onde o Estado usou decretos e leis para impor perdões e esquecer, diferentes grupos e instituições responderam ao desencadear uma batalha pela memória e pela verdade". Nesse sentido, seu uso parte do pressuposto de que a constituição e ressignificação do espaço dos lugares de memória são necessariamente marcadas por algum tipo de disputa entre os atores que delas participam. Assim, essa noção ao mesmo tempo problematiza a ideia de dever de memória (o que deve ser lembrado? com que objetivo? em que momento? de que maneira?), ao mesmo tempo em que coloca em questão a ideia de que existe uma dada vontade de memória (vontade de quem? com que finalidade? Que se manifesta como?).

Isso se percebe na própria escolha por uma narrativa museológica em detrimento de outras narrativas memorialísticas - como outra majoritariamente arquivística, por exemplo - é particularmente interessante, a começar pelo fato de que no caso do MRSP, o principal suporte de memória coletiva é o espaço. Enquanto museu, o MRSP se reconfigura cotidianamente como um espaço de debate acerca de questões de interesse social, que muitas vezes transbordam a historicidade e a temporalidade do prédio e das exposições nele hospedadas. Nesse sentido, torna-se lócus do chamado fato museal, descrito por Neves (2011, p.162) como a "relação dialógica que se estabelece entre o homem (comunidade) e o objeto (referência patrimonial) em um cenário institucionalizado (território de intervenção museológica)". É nesse movimento dialógico que o MRSP, por meio de um projeto museológico amplo e 
REFLEXÕES SOBRE A PRODUÇÃO DE ESPAÇOS DE MEMÓRIA EM CONTEXTOS DE JUSTIÇA DE

TRANSIÇÃO: O CASO DO MEMORIAL DA RESISTÊNCIA DE SÃO PAULO

Talita de Oliveira Trindade | Alessandra de Sá Mello da Costa

processual (organizing), opera um "trabalho de enquadramento da memória" (Pollak, 1989, p. 6), que diz respeito à ressignificação contínua do passado a partir de questões atuais que participam da agenda dos tutores dessa memória.

\section{Organização contínua da memória coletiva}

Ao contrário da noção tradicionalmente adotada em Estudos Organizacionais de que o espaço é fixo e não dialético (TAYLOR E SPICER, 2007), assumimos que o espaço do MRSP é dinâmico e representativo tanto de disputas de poder, tanto quanto é produto daqueles que o constituem e o experienciam. O espaço é, portanto, uma categoria necessária para o tipo de enquadramento proposto pelo projeto museológico de institucionalização da memória. Rigney (2008) sugere que a função comemorativa dos memoriais somente é mantida quando as narrativas do passado são mantidas vivas e em constante comunicação com questões presentes. Atualmente, o MRSP atua em seis diferentes frentes, que garantem o diálogo entre

\section{$\underline{\text { Ação Cultural }}$}

Este programa permite que o MRSP se articule com outros agentes interessados na promoção de debates acerca de questões de ordem política mais amplas, relacionadas à temática da repressão e resistência políticas. Fazem parte da agenda de ações culturais: (1) Sábados Resistentes (ação regular, promovida em parceria com o Núcleo Memória), (2) Cinema da Resistência, (3) Semana Nacional de Museus e Primavera dos Museus (em articulação com o Ministério da Cultura) e (4) Projetos multimídia/intervenções artísticas, em conjunto com a Pinacoteca do Estado de São Paulo.

Os Sábados Resistentes são um bom exemplo da abrangência em funcionamento desde 2008, o evento ocorre duas vezes por mês no auditório do Memorial e tem uma média de 100 participante por evento. As temáticas são 
REFLEXÕES SOBRE A PRODUÇÃO DE ESPAÇOS DE MEMÓRIA EM CONTEXTOS DE JUSTIÇA DE

TRANSIÇÃO: O CASO DO MEMORIAL DA RESISTÊNCIA DE SÃO PAULO

Talita de Oliveira Trindade | Alessandra de Sá Mello da Costa

diversas, mas sempre em torno de temas que dialogam com a tríade verdadememória-justiça.

\section{Centro de Referência}

O Centro de Referência é uma linha programática em desenvolvimento, que pretende servir como plataforma para estudiosos das temáticas tratadas pelo MRSP. Por meio do Centro de Referência, atualmente, é mantida uma biblioteca para consulta local - Biblioteca Walter Wey. Também com função educativa, o programa abriga a articulação com outras instituições preservacionistas, como o Núcleo Memória e a Coalizão Internacional de Sítios de Consciência.

\section{Coleta Regular de Testemunhos}

Este programa visa a expansão do conhecimento sobre a história e funcionamento do Deops/SP “a partir dos testemunhos de ex-presos e perseguidos políticos e de familiares de mortos e desaparecidos, bem como de outros cidadãos que trabalharam nessa instituição ou que por dever do ofício a frequentaram" (Memorial da Resistência de SP, s.d.). Assim, ao ampliar o acervo de narrativas, a coleta regular também acaba por fornecer "novos subsídios às demais ações do Memorial, possibilitando novas escolhas para a exposição de longa duração, as mostras temporárias, material educativo e ações culturais" (FECHER, 2015, p. 104).

\section{Lugares de Memória}

Este programa é a principal frente de trabalho extramuros do MRSP e é composto por quatro projetos, quais sejam: (1) "Inventário dos lugares de memória: a educação para os direitos humanos por meio do patrimônio", (2) exposição itinerante "Lugares da Memória - resistência e repressão em São Paulo"; (3) sinalização dos lugares da memória, e (4) Museu de Percurso. Com 
REFLEXÕES SOBRE A PRODUÇÃO DE ESPAÇOS DE MEMÓRIA EM CONTEXTOS DE JUSTIÇA DE

TRANSIÇÃO: O CASO DO MEMORIAL DA RESISTÊNCIA DE SÃO PAULO

Talita de Oliveira Trindade | Alessandra de Sá Mello da Costa

caráter de preservação, o programa identifica e inventaria locais de resistência e de repressão com base nos princípios de preservação de memória (FECHER, 2015).

\section{Programa de Ação Educativa}

As ações educativas são responsáveis por boa parte dos esforços empreendidos pelo MRSP, além de absorver o maior número de pessoal que hoje atua no Memorial. As ações educativas são consideradas essenciais para a atuação do MRSP e exercerem um papel fundamental na ressignificação do espaço e da temática da resistência.

Elas envolvem visitas guiadas no Memorial, ações com professores de todos os níveis, encontros com educadores e profissionais do Turismo, rodas de conversa e uma série de outras atividades que ancorem e consolidam princípios democráticos (Decreto no 46.900 de 5/7/2002, que estabeleceu o Memorial da Liberdade). Nesse sentido, os esforços empreendidos pelas ações educativas garantem estabilidade e longevidade às memórias ali narradas e compartilhadas.

A presença dos ex-prisos políticos é constante, o que mantém o diálogo entre gerações recorrente e dinâmico. Nesse sentido, "a participação do grupo que viveu naquele espaço e vivenciou as experiências do DEOPS e da ditadura surge como importante fator propulsor da reflexão política a que se propõe o MRSP" (FECHER, 2015, p. 108). 


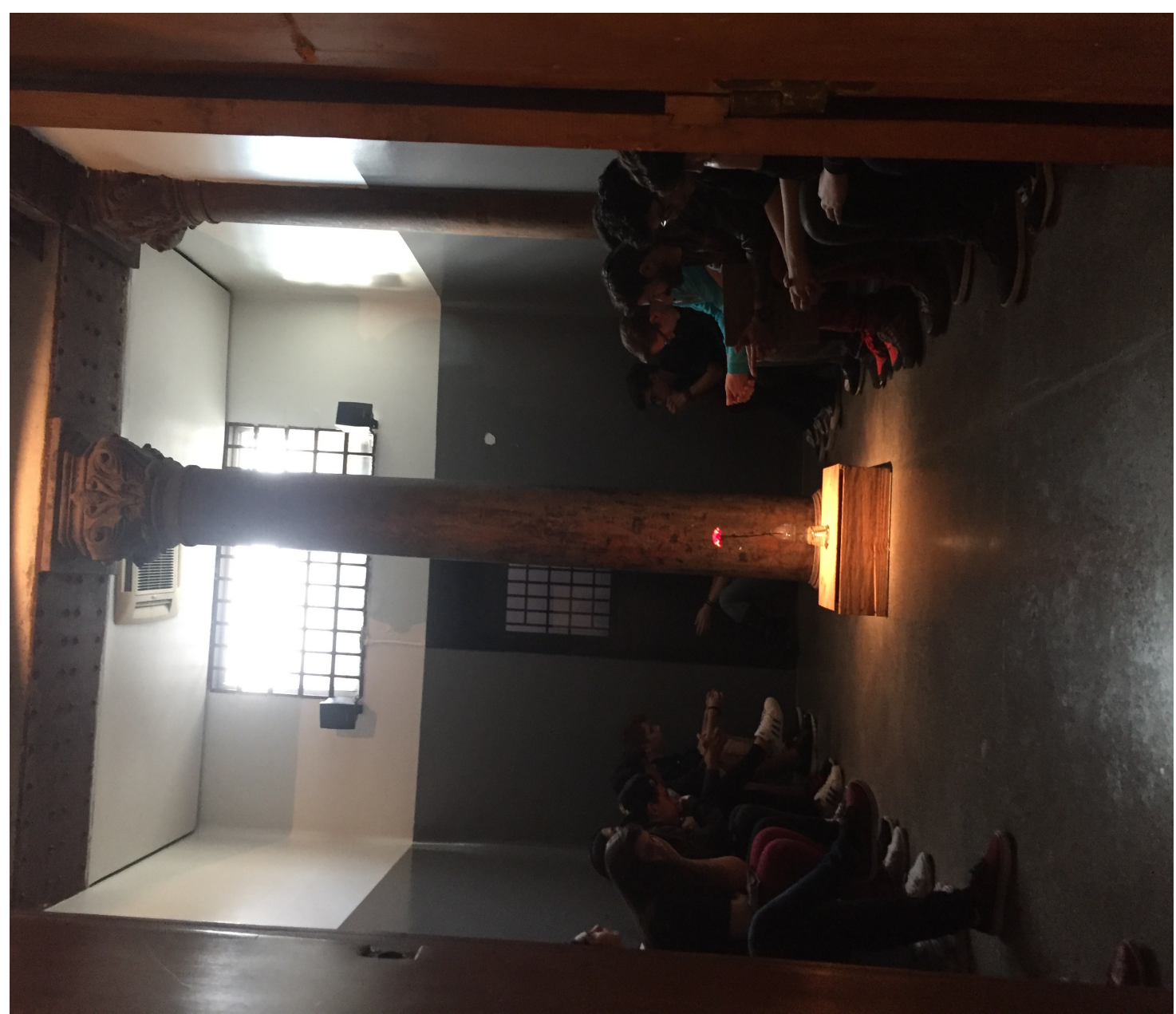

Figura 9: Ação Educativa (Visita técnica ao MRSP, agosto/2017)

O conjunto prisional atualmente possui quatro celas abertas para visitação, sendo a quarta cela (Figura 9) um dos espaços considerados mais expressivos pelos visitantes. Após visitarem os antigos espaços de tortura, os visitantes são dirigidos para a cela quatro, onde se deparam com um cravo vermelho, natural, gentilmente colocado em uma garrafa plástica, que parece repousar sobre uma caixa de frutas, em uma sala com luz baixa. Segundo relatado por Maurice Politi em entrevista ${ }^{4}$, não há consenso entre os ex-presos 
políticos e seus familiares quanto a esta representação, ainda que tenha-se optado por utilizá-la como representação de uma narrativa ressignificada em torno das ideias de militância e resistência.

[O cravo foi] "construído" para simbolizar a solidariedade, um conceito sempre presente nos testemunhos dos que estiveram encarcerados, colaborando para a sobrevivência diária. [...] $] \mathrm{O}$ cravo representa, em certa medida, o que já havia sido defendido por Moutinho: o objeto construído para comunicar as ideias, que apelam aos sentidos, ao saber, à emoção e à memória; e dependerá das experiências e repertórios de cada visitante para sua fruição; de alguma forma, despertará a vontade de conhecer. E ele não está exposto em uma vitrina e nem tem seu significado e/ou uso inscrito em uma etiqueta explicativa. Está à disposição. Segundo os ex-presos, também mostra "que a humanidade venceu" (NEVES, 2015, p. 116-7).

Nesta mesma cela, os visitantes ainda têm acesso à exibição de um testemunho em áudio, que que relata práticas violação de direitos humanos ocorridas naquele espaço.

\section{Programa de Exposições}

As exposições acontecem em duas modalidades: (1) exposições de longa duração, organizadas em torno dos três eixos temáticos do Memorial (controle, repressão e resistência), e (2) exposições temporárias, normalmente organizadas a partir das exposições de longa duração. Há, ainda, as exposições itinerantes, em articulação com o programa Lugares da Memória, que fazem parte de um conjunto de iniciativas extramuros realizadas pela equipe do MRSP envolvendo, também, as ações educativas.

O calendário do MRSP prevê três exposições temporárias anualmente, sendo pelo menos uma delas em torno de temáticas relacionadas à América Latina e/ou ao Programa de Residência Artística.

Entrevista realizada pelas autoras durante um Sábado Resistente, em maio/2016. 


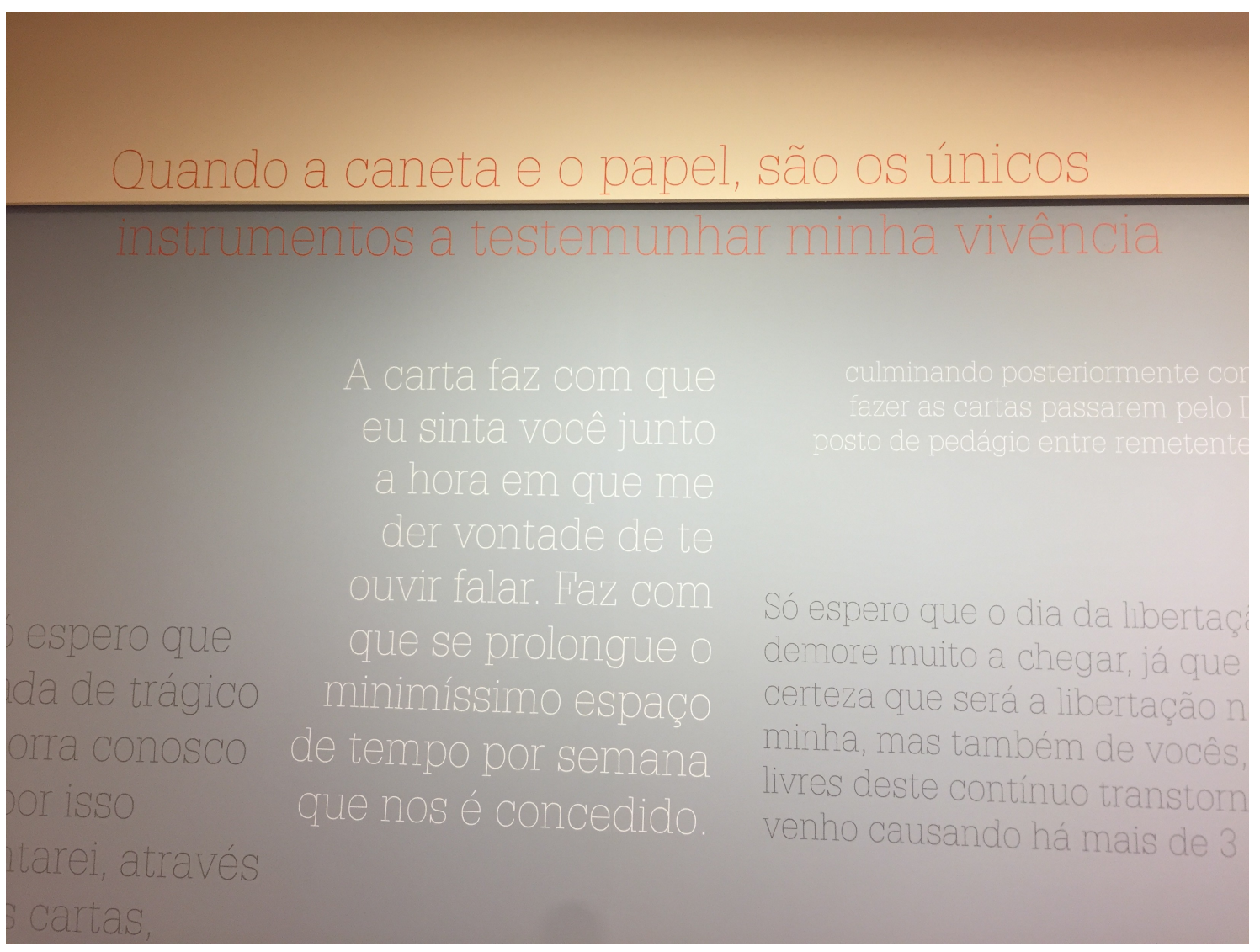

Figura 10: Exposição Carta Aberta (Visita técnica ao MRSP, maio/2017)

\section{Reflexões finais}

Este artigo se propôs apresentar o processo de formação do MRSP, tendo em vista a problematização dos lugares de memória relacionados à justiça de transição na América do Sul. Observamos que as mobilizações em torno dos usos e apropriações do prédio originalmente ocupado pelo antigo DEOPS/SP se desenvolveram paralelamente às demandas sociais pela revisão dos termos de anistia, tendo em vista verdade e justiça - para além das dualidades "impunidade e esquecimento", "liberdade e reparação". Entendemos que a conjuntura social e política em que essas articulações aconteceram funcionou em grande parte como um catalizador para que se chegasse ao que desde 2009 
REFLEXÕES SOBRE A PRODUÇÃO DE ESPAÇOS DE MEMÓRIA EM CONTEXTOS DE JUSTIÇA DE

TRANSIÇÃO: O CASO DO MEMORIAL DA RESISTÊNCIA DE SÃO PAULO

Talita de Oliveira Trindade| Alessandra de Sá Mello da Costa

se reconhece como o Memorial da Resistência de São Paulo, inclusive com trocas sucessivas do seu léxico de designação. Outros esforços de memorialização não foram tão bem-sucedidos, como é o caso, por exemplo, da transformação do prédio onde funcionou o DOPS/RJ em um museu em memória das vítimas da ditadura, conforme anunciado pelo governo do estado em 2013. Em lugar disso, o prédio centenário hospeda o Museu da Polícia Civil em um de seus andares.

Todo o processo de constituição do MRSP evidencia seu papel na legitimação de atores sociais demandantes de reparação, verdade e justiça, quanto na própria reparação simbólica das vítimas do regime militar que passaram pelo DEOPS/SP. Isso se deu tanto por meio da criação dos canais de escuta de memórias até então silenciadas, quanto por meio da garantia de acesso das vítimas, familiares e visitantes a uma experiência mnemónica que transborda o espaço do prédio, ao mesmo tempo em que não seria possível em outro lugar trata-se do prédio como suporte de memória coletiva.

Cotidianamente, o MRSP utiliza-se das suas diversas frentes de atuação para construir e compartilhar memórias por meio da organização e ressignificação constante do espaço e da reflexão sobre as práticas de violação dos direitos humanos ali perpetradas. As ações educativas são particularmente importantes na medida em que promovem a politização em torno dos efeitos desses eventos, exercendo assim uma dupla função: (a) formativa (e, nesse sentido, "humanizadora", particularmente das gerações temporalmente distantes dos eventos ocorridos durante regime militar), e (b) normativa (uma vez que comunica novas leituras sobre repressão e resistência) (ASSMANN, 2011). Essas funções cooperam com a construção da chamada "Cultura do Nunca Mais" (NÚCLEO MEMÓRIA, 2011), em torno da qual se articulam diversas organizações e movimentos sociais, que demandam verdade e justiça.

Por fim, pensar esses lugares como territórios de memória chama a atenção para as tensões presentes desde a sua constituição até a gestão dessas memórias 
REFLEXÕES SOBRE A PRODUÇÃO DE ESPAÇOS DE MEMÓRIA EM CONTEXTOS DE JUSTIÇA DE

TRANSIÇÃO: O CASO DO MEMORIAL DA RESISTÊNCIA DE SÃO PAULO

Talita de Oliveira Trindade | Alessandra de Sá Mello da Costa

no tempo presente. A escolha de uma agenda implica necessariamente a priorização de temas, associações, negativas e a produção de novos silenciamentos, cujos efeitos também precisam ser problematizados.

\section{Referências}

AGUILERA, C. (2015) Memories and silences of a segregated city: Monuments and political violence in Santiago, Chile, 1970-1991. Memory Studies 8(1) 102114.

ABRÃO, P., TORELLY, M. Mutações do conceito de anistia na Justiça de Transição brasileira: a terceira fase da luta pela anistia In: Justiça de transição: análises comparadas Brasil-Alemanha (Org.) Cornelius Prittwitz [et al.]; Antonio Martins [et al.]. Brasília: Ministério da Justiça, Comissão de Anistia, 2015

ALEXANDER, J. (2011) The collective memory reader. Edited by Jeffrey K. Olick, Vered Vinitzky-Seroussi, and Daniel Levy. Oxford University Press, p. 307-310.

ALLEN, M.; BROWN, S. (2016). Memorial meshwork: The making of the commemorative space of the Hyde Park $7 / 7$ Memorial. Organization 23 (1) 1028 .

ALLEN, Matthew; BROWN, Steven D. (2016) Memorial meshwork: The making of the commemorative space of the Hyde Park 7/7 Memorial, Organization, 23(01), 10-28.

ALMEIDA, P.C. (2014). Lugar de memória da resistência: verdade e negociação no processo de tombamento do prédio do DEOPS/SP. In: Thiesen, I. Documentos Sensíveis: Informação, Arquivo e Verdade na Ditadura de 1964. Rio de Janeiro: 7 Letras.

ANTEBY, M.; MOLNAR, V. (2012) Collective Memory meets organizational identity: Remembering to Forget in a Firm's Rhetorical History. Academy of Management Journal, 55(3): 515-540.

ASSMANN, J. (2011) The collective memory reader edited by Jeffrey K. Olick, Vered Vinitzky-Seroussi, and Daniel Levy. Oxford University Press, p. 209-220.

Casey, A.; Oliveira, F. (2011). Reflections on Organizational Memory and Forgetting. Journal of Management Inquiry 20 (3) 305-310.

CATELA, L. (2001) No habrá flores en la tumba del pasado. Las experiencias de reconstrucción del mundo de los familiares de desaparecidos. La Plata, Argentina: Ediciones Al Margen.

Revista Brasileira de Estudos Organizacionais .v. 4, n. 2, p. 407-436, dez. 2017, eISSN: 2447-4851

Doi 10.21583/2447-4851.rbeo.2017.v4n2.105

Sociedade Brasileira de Estudos Organizacionais 
CONTE, G. (2015) A topography of memory: Reconstructing the architectures of terror in the Argentine dictatorship, Memory Studies, 8(1) 86-101.

COSTA, A.S.M.; SILVA, M.A.C. (2017) Novas Fontes, Novas Versões: Contribuições do Acervo da Comissão Nacional da Verdade, Revista de Administração Contemporânea (RAC), 21(2) 163-183.

DECKER, S. (2014) Solid intentions: An archival ethnography of corporate architecture and organizational remembering. Organization 21 (4) 514-542.

DRAPER, S. (2015) Against depolitization: Prison- museums, escape memories, and the place of rights, Memory Studies, 8(1) 62-74.

EASTERBY-SMITH, M.; LYLES, M. (2011) In Praise of Organizational Forgetting. Journal of Management Inquiry 20 (3) 311-316.

FECHER, V. (2015) A história é de todos nós: narrativas sobre a formação do memorial da resistência. Dissertação de mestrado. Universidade de Brasília, Brasília, Brasil.

FELDMAN, R.; FELDMAN, S. (2006) What links the chain: an essay on organizational remembering as practice. Organization 13(6): 861-887.

FIEDLER, M.; WELPE, I. (2010); “How do organizations remember? The influence of organizational structure on organizational memory", Organization Studies, 31(4), 381-407.

GABRIEL, Y., STOKES, P. (2010) Engaging with genocide: the challenge for organization and management studies, Organization 17(4), 461-480.

HALBWACHS, M. (1992). On collective memory: edited, translated, and with an introduction by Lewis A. Coser. The University of Chicago Press.

MARTIN DE HOLAN, P.; PHILLIPS, N. (2004b) Organizational forgetting as strategy. Strategic Organization 2 (4): 423-433.

MENA, S., RINTAMÄKI, J., FLEMING, P., \& SPICER, A. (2016) On the Forgetting of Corporate Irresponsibility. Academy of Management Review, 41(4): 720-738, 2016.

NEVES, K. (2015) A potencialidade dos lugares de memoria sob uma perspectiva museológica processual: um estudo de caso. $O$ memorial de Resistência de São Paulo. Dissertação de mestrado. Universidade Lusófona de Humanidades e Tecnologia. Faculdade de Ciências Sociais e Humanas. Departamento de Museologia. Lisboa, Portugal.

NISSLEY; N.; CASEY, A. (2002) The Politics of the Exhibition: Viewing Corporate Museums Through the Paradigmatic Lens of Organizational Memory'. British Journal of Management, 17: 535-543.

NORA, P. (1993) Entre memória e História: a problemática dos lugares. Projeto História, São Paulo, n. 10. 
REFLEXÕES SOBRE A PRODUÇÃO DE ESPAÇOS DE MEMÓRIA EM CONTEXTOS DE JUSTIÇA DE TRANSIÇÃO: O CASO DO MEMORIAL DA RESISTÊNCIA DE SÃO PAULO Talita de Oliveira Trindade | Alessandra de Sá Mello da Costa

NÚCLEO DE PRESERVAÇÃO DA MEMÓRIA POLÍTICA (2011). A Comissão da Verdade no Brasil. Por que, $O$ que é, $O$ que temos de fazer? São Paulo: Núcleo Memória.

OLICK, J. (1999) Collective Memory: The Two Cultures. Sociological Theory $17: 333-348$.

OLICK, J.K.; ROBBINS, J. (1998) Social Memory Studies: From “Collective Memory" to the Historical Sociology of Mnemonic Practices. Annual Review of Sociology 24: 105-140, 1998.

POLLAK, M. (1989) Memória, Esquecimento, Silêncio. Estudos históricos, Rio de Janeiro, vol.2, n. 3, p. 3-15.

RIGNEY, A. (2008) Divided pasts: A premature memorial and the dynamics of collective remembrance. Memory Studies (1): 89-97, 2008.

ROWLINSON, M; BOOTH, C.; Delahaye, A.; Procter, S. Social remembering and organizational memory. Organization Studies 31, n.1, p. 69-87, 2010.

SCHREMPF-STIRLING, J.; Palazzo, G.; Phillips, R. A. (2016) Historic Corporate Social Responsibility, Academy of Management Review, 41(4), 700-719.

SOARES, I. V. P.; QUINALHA, R. H. (2011) Lugares de memória no cenário brasileiro da justiça de transição. Revista Internacional de Direito e Cidadania, 10, jun. 2011, 75-86.

TAYLOR, S.; SPICER, A. (2007) Time for space: A narrative review of research on organizational spaces. International Journal of Management Reviews 9 (4) 325-346.

WALSH, J.P.; UNGSON, G.R. (1991) Organizational Memory. The Academy of Management Review 16, n.1, p. 57-91.

ZERUBAVEL, E. (2011) The collective memory reader edited by Jeffrey K. Olick, Vered Vinitzky-Seroussi, and Daniel Levy. Oxford University Press, p. 221-224.

Submetido em: 20/11/2017

Aprovado em: 07/12/2017 